\title{
Short communication: Heritability estimates for susceptibility to Mycobacterium avium ssp. paratuberculosis infection in Chinese Holstein cattle
}

\author{
Y. Gao, ${ }^{*}$ J. Cao,† S. Zhang, ${ }^{*}$ Q. Zhang, ${ }^{*}$ and D. Sun*1 \\ *Laboratory of Animal Genetics, Breeding and Reproduction, Ministry of Agriculture of China, National Engineering Laboratory of Animal Breeding, \\ College of Animal Science and Technology, and \\ †College of Veterinary Medicine, China Agricultural University, Beijing 100193, China
}

\begin{abstract}
Paratuberculosis in ruminants, which is caused by Mycobacterium avium ssp. paratuberculosis (MAP), is a contagious, chronic enteric disease associated with economic losses, animal welfare, and health implications in dairy cattle production. In this study, we estimated the variance components and heritability of susceptibility to MAP infection in Chinese Holstein cattle. We collected 4,937 serum samples from cows in 7 dairy herds in the Beijing region of China and used the ELISA test to detect antibodies to MAP. Three statistical models were implemented to estimate heritabilities: (1) a linear model (ELISA sample-to-positive ratios as a continuous trait); (2) a binary threshold model (positive/negative from ELISA results); and (3) an ordered threshold model (ELISA results as an ordered categorical model with categories 1 to 5 corresponding to negative, uncertain, mildly positive, intermediate positive, and strongly positive). The heritability estimates ranged from 0.0389 to 0.1069 , indicating that genetic factors affect MAP infection susceptibility in Chinese Holstein cattle.
\end{abstract}

Key words: paratuberculosis, Johne's disease, heritability, Chinese Holstein

\section{Short Communication}

Paratuberculosis, or Johne's disease (JD) as it is commonly known, is caused by Mycobacterium avium ssp. paratuberculosis (MAP) and is a contagious, chronic, enteric disease of ruminants (Clarke, 1997). Animals suffering from JD show several classic clinical signs including diarrhea and weight loss and they eventually die. Ten percent of infected cows die of this disease every year, and the remaining $90 \%$ of diseased

Received May 31, 2017.

Accepted February 7, 2018.

${ }^{1}$ Corresponding author: sundx@cau.edu.cn cows are slaughtered (Chen, 2016). Mycobacterium avium ssp. paratuberculosis can hide in many substrates such as colostrum, milk, and feces, from where it can be transmitted to susceptible individuals (Nielsen et al., 2008), with the major route being the fecal-oral route (Lombard, 2011). Since 2000, JD has been reported around the world with an average herd prevalence (the proportion of herds with at least one JD case) between 30 and 50\% (Boelaert et al., 2000; Muskens et al., 2000; Tiwari et al., 2006; NAHMS, 2007; Haghkhah et al., 2008; Defra, 2009; Good et al., 2009; Nielsen, 2009a,b,c). According to recent reports, herd prevalence has reached $91.1 \%$ in the United States (Lombard et al., 2013) and 65.4\% in Egypt (Amin et al., 2015). The associated costs of JD, such as decreased reproductive and productive efficiency and the need for diagnostic testing, have resulted in JD affecting the global dairy industry severely (Ott et al., 1999). Unfortunately, because no effective cure or vaccines for JD exist, the only way to decrease its prevalence is to implement control programs such as those described by Ferrouillet et al. (2009). The main steps of control programs include identifying positive cows using ELISA or other detection methods, isolating them to eliminate transmission routes, and finally eliminating positive cows that show clinical symptoms.

Selection for disease-resistant animals could produce offspring with increased average ability to resist MAP infection; thus, genetic selection for animals with JD resistance would be an effective means to control JD. Several early studies performed on Holstein and Jersey cattle that estimated the heritability of infection with MAP reported estimates ranging from 0.031 to 0.283 (Koets et al., 2000; Mortensen et al., 2004; Gonda et al., 2006; Hinger et al., 2008; Attalla et al., 2010; Berry et al., 2010; van Hulzen et al., 2011; Küpper et al., 2012; Shook et al., 2012; Zare et al., 2014). Despite variable results, these previous studies show that MAPinfection resistance in cattle has a genetic background.

Chinese Holstein cattle are the result of cross breeding between Chinese Yellow cattle and European Holsteins 
over the past 100 yr. Foreign Holstein bulls, semen, and embryos, mainly from the United States, and a few from Canada and Europe, have been continuously imported, and these have been used directly for AI or for crossing with Chinese Holstein cows through planned mating to generate breeding bulls (Sun et al., 2009). According to recent investigations on MAP in large-scale dairy farms in some Chinese provinces, herd-level prevalence of MAP infection has reached 100\% (Sun et al., 2015; Cui et al., 2016) and within-herd prevalence has also gradually increased. To the best of our knowledge, no systematic study to analyze the genetics of susceptibility to MAP infection in Chinese Holstein cattle has been undertaken. To genetically improve resistance to MAP infection, implementation of a comprehensive genetic evaluation is a crucial step. Therefore, the objective of this study was to estimate the heritability of susceptibility to MAP infection based on antibody titers from Chinese Holstein cattle, and to use the data in the context of dairy cattle selection.

The protocols for collecting blood samples from the experimental animals were reviewed and approved by the Institutional Animal Care and Use Committee at China Agricultural University (Permit Number DK996). All the experiments were performed in accordance with the relevant approved guidelines and regulations. In total, 8,214 Chinese Holstein cows from 7 herds at the Beijing Sanyuan Dairy Farm Center were sampled, 4,937 of which were $\leq 24$ mo of age and used for heritability estimation. All cows were fed under the same feeding and management system, and regular quarantine inspections of the herds were conducted so that these 7 herds represented the situation of JD infection status of dairy herds in the Beijing region. Although all 7 herds belong to the Beijing Sanyuan Dairy Farm Centre, there was no movement of animals between the herds because of the strict management system based on regular quarantine inspections twice annually. In addition, there were no records of other diseases such as tuberculosis or subclinical mastitis in the cows included in this study. The cows belonged to 436 sire families with an average of 11.3 daughters per sire. Pedigree relationships for the 4,937 cows were traced back 5 generations. Blood samples $(500 \mu \mathrm{L})$ were collected from the caudal vein of each cow during the regular quarantine inspection of the farms in September 2014. All cows within a herd were sampled on the same day. Serum extracted from blood samples was stored at $4^{\circ} \mathrm{C}$ until testing, which took place within $5 \mathrm{~d}$ of collection. With the ELISA method, the antibody levels in the serum samples were determined using the Mycobacterium paratuberculosis Antibody Test Kit (Idexx Laboratories Inc., Westbrook, ME) following the manufacturer's instructions. The MAP status of an animal was expressed as the sample-to-positive $(\mathbf{S} / \mathbf{P})$ ratio multiplied by 100 : $\mathrm{S} / \mathrm{P}$ ratio $=100 \times[$ (optical density $(\mathrm{OD})$ value of the sample - OD of the negative control)/(OD of a positive sample - OD of the negative control)], where $\mathrm{S} / \mathrm{P} \leq$ 0.45 is negative; $0.45<\mathrm{S} / \mathrm{P}<0.55$ is uncertain; $0.55 \leq$ $\mathrm{S} / \mathrm{P}<1$ is mildly positive; $1 \geq \mathrm{S} / \mathrm{P}<2$ is intermediate positive; and $\mathrm{S} / \mathrm{P}>2$ is strongly positive. Parity levels were from 0 (nulliparous) to 4 ( $\geq$ fourth parity). The ages of the cows sampled ranged from 25 to 162 mo. Ages were grouped in 17 levels by 6-mo intervals (all cows older than 120 mo were in level 21), and $77.17 \%$ of individuals were between 25 and 60 mo old. Three traits were defined for heritability estimation according to the ELISA results: (1) ELISA S/P were taken as a continuous trait; (2) ELISA results were taken as a binary trait $(0=$ negative, $1=$ positive $)$, where mildly positive, intermediate positive, and strongly positive ELISA results were considered ELISA positive (77 uncertain ELISA results were excluded); and (3) ELISA results were taken as an ordered categorical trait with categories 1 to 5 corresponding to negative, uncertain, mildly positive, intermediate positive, and strongly positive, respectively.

We used an animal genetic model and 3 statistical models: a linear model, a binary threshold model, and an ordered threshold model to estimate the variance components. Because of non-normality, log-transformed ELISA S/P ratios were used in the linear model [ELISA $=\log _{10}($ ELISA +0.01$) ; 0.01$ was added to avoid $\left.\log (0)\right]$. Before estimating variance components, a preliminary analysis of the fixed effects including herd and parity was conducted using the different models. The fixed effects for herd and parity showed significant $(P<0.01)$ effects in all 3 models.

The following linear model was used for the analysis of log-transformed ELISA S/P ratios:

$$
y_{i j k n}=p_{i}+h_{j}+a_{k}+e_{i j k n},
$$

where $y_{i j k n}$ is the transformed ELISA S/P ratio, $p_{i}$ is the fixed effect of parity, $h_{j}$ is the fixed effect of herd, $a_{k}$ is the additive genetic effect, and $e_{i j k n}$ is the residual. Random effects were assumed to be normally distributed:

$$
\begin{aligned}
& a \sim N\left(0, \mathbf{A} \sigma_{a}^{2}\right), \\
& e \sim N\left(0, \mathbf{I} \sigma_{e}^{2}\right),
\end{aligned}
$$

where $\mathbf{A}$ is the numerator relationship matrix, $\sigma_{a}^{2}$ represents the individual additive variance, $\mathbf{I}$ is an identity matrix, and $\sigma_{e}^{2}$ represents the residual variance. Variance components were estimated by the DMUAI mod- 
Table 1. Distribution of cow Mycobacterium avium ssp. paratuberculosis (MAP) infection status by herd and parity

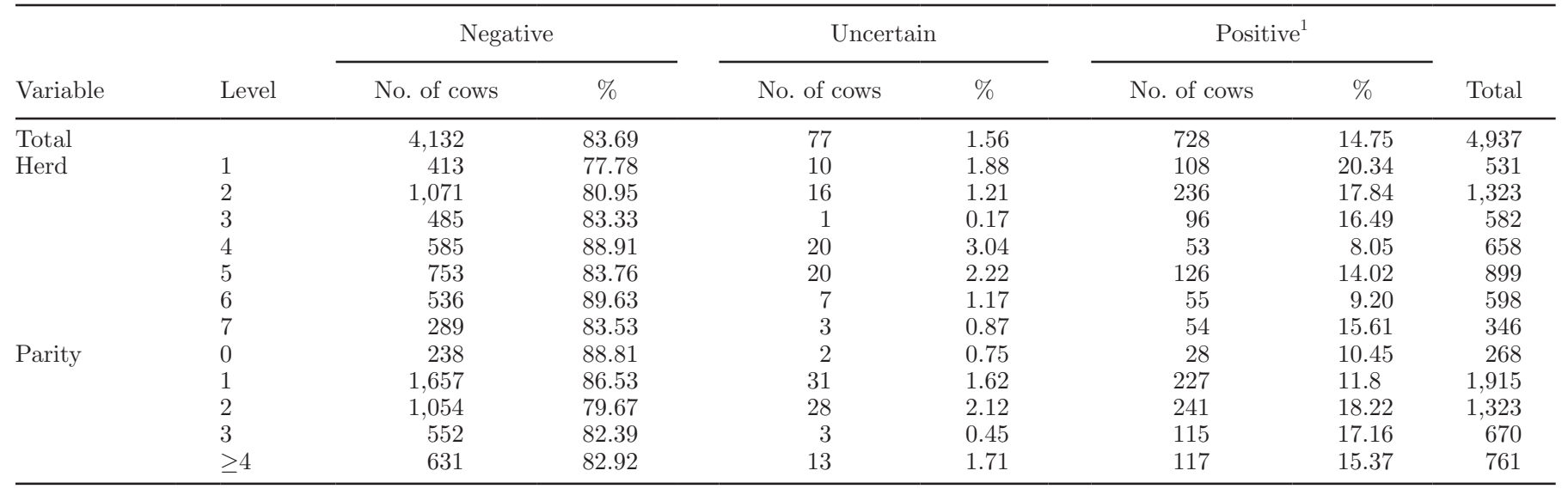

${ }^{1}$ Mildly positive, intermediate positive, and strongly positive ELISA results were considered ELISA positive.

ule using the REML method in the DMU software (Madsen and Jensen, 2013).

In the binary threshold model, only ELISA-negative and ELISA-positive results were used. The estimation of the variance components was carried out by the RJMC module using the Bayesian Markov chain Monte Carlo (MCMC) method in the DMU software (Madsen and Jensen, 2013). The binary threshold model was

$$
l_{i j k n}=p_{i}+h_{j}+a_{k}+e_{i j k n}
$$

where $l_{i j k n}$ is the liability to JD based on ELISA S/P ratios for parity $i$, herd $j$, and animal $k$, and the other parameters are defined above.

In the ordered threshold model, the estimation of the variance components was carried out by the RJMC module using the Bayesian MCMC method in the DMU software (Madsen and Jensen, 2013). The fitted model was

$$
\lambda_{i j k n}=p_{i}+h_{j}+a_{k}+e_{i j k n}
$$

where $\lambda_{i j k n}$ is the liability to JD based on ELISA S/P ratios for parity $i$, herd $j$, and animal $k$, and the other parameters are defined as in the linear model.

Narrow-sense heritability was calculated as

$$
h^{2}=\frac{\sigma_{a}^{2}}{\sigma_{a}^{2}+\sigma_{e}^{2}},
$$

where $\sigma_{a}^{2}$ is the individual additive variance and $\sigma_{e}^{2}$ is the residual variance. Standard errors were reported.

After screening the 4,937 Chinese Holstein cows using ELISA methodology, 728 cows, distributed across the 7 herds, were found to be positive for MAP. The frequency of positive cows across these herds varied from
8.05 to $20.34 \%$, with an average prevalence of $14.51 \%$ (Table 1). Second- and third-parity cows showed the highest positivity rates at 18.22 and $17.16 \%$, respectively (Table 1). The frequency of ELISA-positive cows by age, as shown in Figure 1, varied from 3.23\% (97-102 $\mathrm{mo})$ to $20.83 \%$ (43-48 mo), with the highest frequency recorded between 25 and 96 mo of age. The average frequencies of the 5 categories were $83.69 \%$ (negative), $1.56 \%$ (uncertain), $4.33 \%$ (mildly positive), $8.47 \%$ (intermediate positive), and $1.94 \%$ (strongly positive).

The estimated heritability obtained from the 3 models in this study ranged from 0.0389 (ordered threshold model) to 0.1069 (binary threshold model; Table 2), a finding in line with the range reported in previous studies (0.031 to 0.283). The discrepancies in the estimated heritabilities between these studies may be explained by several factors: (1) the different population sizes, from 3,020 (Koets et al., 2000) to 684,364 (van Hulzen et al., 2011); (2) the different statistical methods (such as linear model vs. threshold model, and sire model vs. animal model); and (3) the different diagnostic tests used to determine infection status. Additionally, infection prevalence in different herds can contribute to variations in the estimated heritability (van Hulzen et al., 2011), and it is known that variance components are population-specific and will not necessarily be the same across different breeds or different populations. The heritabilities estimated in both the linear model $(0.0488 \pm 0.0200)$ and the ordered threshold model $(0.0389 \pm 0.0098)$ were lower than that in the binary threshold model $(0.1069 \pm 0.0394)$. According to the study by Zare et al. (2014), the ELISA S/P ratio as a continuous trait captures a whole spectrum of variations in susceptibility to MAP infection among study animals, whereas classifying study results into binary categories compresses information, which may result in a lower heritability estimate. However, we cannot 
Table 2. Heritability with standard errors and variance component estimates ${ }^{1}$ for different models and data sets

\begin{tabular}{|c|c|c|c|c|}
\hline $\begin{array}{l}\text { No. of } \\
\text { cows }\end{array}$ & Model & $\mathrm{h}^{2} \pm \mathrm{SE}$ & $\mathrm{V}_{\mathrm{A}}$ & $\mathrm{V}_{\mathrm{P}}$ \\
\hline 4,937 & Linear $^{2}$ & $0.0488 \pm 0.0200$ & 0.0156 & 0.3199 \\
\hline 4,860 & Binary threshold ${ }^{3}$ & $0.1069 \pm 0.0394$ & 0.1197 & 1.1197 \\
\hline 4,937 & Ordered threshold ${ }^{4}$ & $0.0389 \pm 0.0098$ & 0.0358 & 0.9214 \\
\hline
\end{tabular}

${ }^{1} \mathrm{~V}_{\mathrm{A}}=$ additive genetic variance; $\mathrm{V}_{\mathrm{P}}=$ phenotypic variance.

${ }^{2}$ Logarithmically transformed ELISA sample-to-positive (S/P) ratios.

${ }^{3}$ Optical density $(\mathrm{OD}) \leq 0.45$ were considered ELISA negative; $0.45<\mathrm{OD}<0.55$ were considered ELISA uncertain and therefore removed from further analysis; OD $\geq 0.55$ were considered ELISA positive.

${ }^{4}$ The 5 categories (negative, uncertain, mildly positive, intermediate positive, and strongly positive) were defined according to the ELISA $\mathrm{S} / \mathrm{P}$ ratios.

be sure that a binary model would result in a loss of information that affects mostly the genetic component of the total variance. Binarization is a simplification of the original problem, but heritability may not necessarily be smaller. In the study by Hinger et al. (2008), the estimated heritability from the linear model was larger than that from the binary model, whereas the opposite was found by Berry et al. (2010). According to Zare et al. (2014), the estimated heritability from linear model was lower than that from the ordered threshold model. Different from their results, the estimated heritability in our linear model $(0.0498 \pm 0.0200)$ was higher than that from the ordered threshold model $(0.0389 \pm$ 0.0098). However, Attalla et al. (2010) reported that there was no evidence to recommend a linear model over a threshold model for genetic evaluation. In the current study, the non-normality of the ELISA S/P ratio, even after transformation, may have introduced bias into heritability estimates.
In addition, we estimated heritability in 3 age groups (25-36 mo, 37-48 mo, and >48 mo) based on 3 models with almost 1,500 cows in each group (Table 3). The heritabilities estimated by linear and ordered threshold models were consistent with the estimates in previous studies (Koets et al., 2000; Mortensen et al., 2004; Gonda et al., 2006; Hinger et al., 2008; Attalla et al., 2010; Berry et al., 2010; van Hulzen et al., 2011; Küpper et al., 2012; Shook et al., 2012; Zare et al., 2014). In addition, we observed that the additive genetic variance did not reach convergence in the binary threshold model so the estimated heritability was higher than that in other 2 models (0.9965 vs. 0.1712 or 0.1096$)$ in the age group of 25 to $36 \mathrm{mo}$, indicating that the estimate of 0.9965 was not convincing. The reason for this is likely that the number of cows in this age group was relatively small for heritability estimation.

Several diagnostic tests were used in the early studies on MAP. In the first study to estimate the heritability

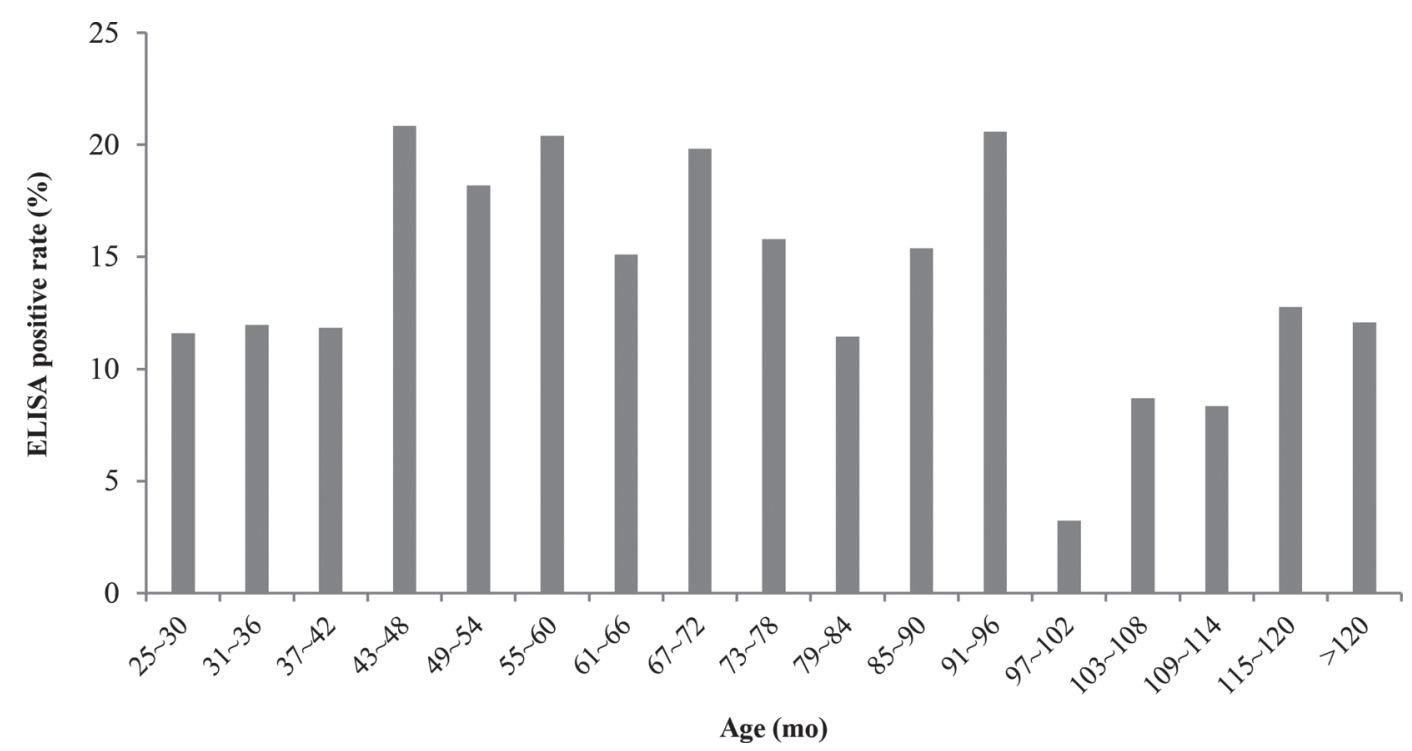

Figure 1. Estimated frequency of Mycobacterium avium ssp. paratuberculosis (MAP) infection-positive cows by age (mo). 
Table 3. Heritability by age with standard errors and variance component estimates ${ }^{1}$ for different models and data sets

\begin{tabular}{lllrrr}
\hline Model & $\begin{array}{l}\text { Age } \\
(\mathrm{mo})\end{array}$ & $\begin{array}{c}\text { No. of } \\
\text { cows }\end{array}$ & $\mathrm{h}^{2} \pm \mathrm{SE}$ & $\mathrm{V}_{\mathrm{A}}$ & \multicolumn{1}{c}{$\mathrm{V}_{\mathrm{P}}$} \\
\hline Linear $^{2}$ & $25-36$ & 1,745 & $0.1712 \pm 0.0615$ & 0.0505 & 0.2948 \\
& $37-48$ & 1,310 & $0.0433 \pm 0.0454$ & 0.014 & 0.3241 \\
Binary threshold $^{3}$ & $>48$ & 1,882 & $0.0076 \pm 0.0249$ & 0.0026 & 0.3391 \\
& $25-36$ & 1,724 & $0.9965 \pm 0.0030$ & 285.1671 & 286.1671 \\
& $37-48$ & 1,276 & $0.1445 \pm 0.0817$ & 0.1689 & 1.1689 \\
Ordered threshold $^{4}$ & $>48$ & 1,860 & $0.1381 \pm 0.0688$ & 0.1602 & 1.1602 \\
& $25-36$ & 1,745 & $0.1096 \pm 0.0284$ & 0.0372 & 0.3399 \\
& $37-48$ & 1,310 & $0.1041 \pm 0.0283$ & 0.0399 & 0.3827 \\
& $>48$ & 1,882 & $0.0961 \pm 0.0255$ & 0.0449 & 0.4672 \\
\hline
\end{tabular}

${ }^{1} \mathrm{~V}_{\mathrm{A}}=$ additive genetic variance; $\mathrm{V}_{\mathrm{P}}=$ phenotypic variance.

${ }^{2}$ Logarithmically transformed ELISA sample-to-positive $(\mathrm{S} / \mathrm{P})$ ratios.

${ }^{3}$ Optical density $(\mathrm{OD}) \leq 0.45$ were considered ELISA negative; $0.45<\mathrm{OD}<0.55$ were considered ELISA uncertain and therefore removed from further analysis; OD $\geq 0.55$ were considered ELISA positive.

${ }^{4}$ The 5 categories (negative, uncertain, mildly positive, intermediate positive, and strongly positive) were defined according to the ELISA S/P ratios.

of susceptibility to MAP, Koets et al. (2000) detected 3,020 MAP-positive Dutch dairy cattle based on postmortem data. Although postmortem analysis is one of the most accurate methods, it is not applicable for large-scale and routine disease diagnosis. In subsequent research, 3 detection methods were used to determine the MAP status of dairy cows. The methods included milk ELISA (Mortensen et al., 2004; Attalla et al., 2010; van Hulzen et al., 2011), fecal culture (Gonda et al., 2006; Küuper et al., 2012; Zare et al., 2014), and serum ELISA (Gonda et al., 2006; Hinger et al., 2008; Berry et al., 2010; Shook et al., 2012; Zare et al., 2014). When methods differ in their sensitivities, this will cause variation in the MAP status of the cows. Eamens et al. (2000) suggested that there is a low correlation between fecal culture and serum ELISA in judging MAP status, whereas Gonda et al. (2006) concluded that the analysis results for serum and milk ELISA and fecal culture showed similar heritabilities. In addition, Hinger et al. (2008) and Küpper et al. (2012) used serum ELISA and fecal culture to determine the MAP status of German Holstein cattle and both methods showed the same tendency of MAP prevalence over age groups. Zare et al. (2014) estimated the heritability for susceptibility to MAP infection in US Jersey cattle using serum ELISA and fecal culture simultaneously. Similar heritabilities for both diagnostic tests were obtained, but the authors emphasized that the heritability estimated from the combination of serum ELISA and fecal culture (0.197) might be closer to the true heritability value.

Whitlock and Buergelt (1996) classified MAP infections into 4 categories according to the appearance of clinical signs and disease severity (i.e., "silent" infection, subclinical disease, clinical disease, and advanced clinical disease). They found that after newborns or heifers were infected with MAP, it took $2 \mathrm{yr}$ for them to show clinical signs of the disease. In the present study, most ELISA-positive cows were aged 25 to $96 \mathrm{mo}$, a finding consistent with the known infection patterns of JD. Additionally, the age distribution of MAP-positive animals was consistent with the results of Hinger et al. (2008) and Küpper et al. (2012).

In conclusion, this is the first study to estimate the heritability of susceptibility to MAP infection in Chinese Holstein cattle. The estimated heritability ranged from 0.0389 to 0.1069 , which is in agreement with the range reported in previous studies. Although the heritability value is low, it should be possible to select individuals in breeding programs for resistance to MAP infections as a means of controlling the prevalence of JD.

\section{ACKNOWLEDGMENTS}

This work was supported financially by the National Natural Science Foundation (31472065, Beijing), Beijing Dairy Industry Innovation Team (BAIC06-2018, Beijing), National Science and Technology Program of China (2013AA102504, Beijing), and the Program for Changjiang Scholar and Innovation Research Team in University (IRT1191, Beijing). We thank Sandra Cheesman, PhD, from Liwen Bianji, Edanz Group China (www.liwenbianji.cn/ac), for editing the English text of a draft of this manuscript.

\section{REFERENCES}

Amin, A. S., C. Y. Hsu, S. F. Darwish, P. Ghosh, E. M. AbdEl-Fatah, T. S. Behour, and A. M. Talaat. 2015. Ecology and genomic features of infection with Mycobacterium avium subspecies paratuberculosis in Egypt. Microbiology 161:807-818. https://doi.org/10 $.1099 /$ mic.0.000051. 
Attalla, S. A., A. J. Seykora, J. B. Cole, and B. J. Heins. 2010. Genetic parameters of milk ELISA scores for Johne's disease. J. Dairy Sci. 93:1729-1735. https://doi.org/10.3168/jds.2009-2625.

Berry, D. P., M. Good, P. Mullowney, A. R. Cromie, and S. J. More. 2010. Genetic variation in serological response to Mycobacterium avium subspecies paratuberculosis and its association with performance in Irish Holstein-Friesian dairy cows. Livest. Sci. 131:102107. https://doi.org/10.1016/j.livsci.2010.03.007.

Boelaert, F., K. Walravens, P. Biront, J. P. Vermeersch, D. Berkvens, and J. Godfroid. 2000. Prevalence of paratuberculosis (Johne's disease) in the Belgian cattle population. Vet. Microbiol. 77:269-281.

Chen, F. 2016. Epidemiological survey of Johne's disease in Beijing dairy herds and initial implementation of control program. MS Thesis. China Agricultural Univ., Beijing.

Clarke, C. J. 1997. The pathology and pathogenesis of paratuberculosis in ruminants and other species. J. Comp. Pathol. 116:217-261.

Cui, J. L., Y. C. Zhao, T. Wu, and Z. Y. Shen. 2016. Epidemiological investigation of bovine paratuberculosis in scaled dairy farms in some provinces of China in 2015. Anim. Husb. Feed Sci. 37:97-99.

Defra. 2009. SB4022: An Integrated Strategy to Determine the Herd Level Prevalence of Johne's Disease in the UK Dairy Herd. Department for Environment, Food and Rural Affairs (Defra). Accessed Apr. 15, 2017. http://webarchive.nationalarchives.gov .uk/20130402151656/http://archive.defra.gov.uk/foodfarm/ farmanimal/diseases/atoz/johnes/index.htm.

Eamens, G. J., R. J. Whittington, I. B. Marsh, M. J. Turner, V. Saunders, P. D. Kemsley, and D. Rayward. 2000. Comparative sensitivity of various faecal culture methods and ELISA in dairy cattle herds with endemic Johne's disease. Vet. Microbiol. 77:357-367. https://doi.org/10.1016/S0378-1135(00)00321-7.

Ferrouillet, C., S. J. Wells, W. L. Hartmann, S. M. Godden, and J. Carrier. 2009. Decrease of Johne's disease prevalence and incidence in six Minnesota, USA, dairy cattle herds on a long-term management program. Prev. Vet. Med. 88:128-137. https://doi.org/10 .1016/j.prevetmed.2008.08.001.

Gonda, M. G., Y. M. Chang, G. E. Shook, M. T. Collins, and B. W. Kirkpatrick. 2006. Genetic variation of Mycobacterium avium ssp. paratuberculosis infection in US Holsteins. J. Dairy Sci. 89:18041812. https://doi.org/10.3168/jds.S0022-0302(06)72249-4.

Good, M., T. Clegg, H. Sheridan, D. Yearsely, T. O'Brien, J. Egan, and P. Mullowney. 2009. Prevalence and distribution of paratuberculosis (Johne's disease) in cattle herds in Ireland. Ir. Vet. J. 62:597-606. https://doi.org/10.1186/2046-0481-62-9-597.

Haghkhah, M., M. Ansari-Lari, A. M. Novin-Baheran, and A. Bahramy. 2008. Herd-level prevalence of Mycobacterium avium subspecies paratuberculosis by bulk-tank milk PCR in Fars province (southern Iran) dairy herds. Prev. Vet. Med. 86:8-13. https://doi .org/10.1016/j.prevetmed.2008.03.010.

Hinger, M., H. Brandt, and G. Erhardt. 2008. Heritability estimates for antibody response to Mycobacterium avium subspecies paratuberculosis in German Holstein cattle. J. Dairy Sci. 91:3237-3244. https://doi.org/10.3168/jds.2008-1021.

Koets, A. P., G. Adugna, L. L. Janss, H. J. van Weering, C. H. Kalis, G. H. Wentink, V. P. Rutten, and Y. H. Schukken. 2000. Genetic variation of susceptibility to Mycobacterium avium ssp. paratuberculosis infection in dairy cattle. J. Dairy Sci. 83:2702-2708. https://doi.org/10.3168/jds.S0022-0302(00)75164-2.

Küpper, J., H. Brandt, K. Donat, and G. Erhardt. 2012. Heritability estimates for Mycobacterium avium subspecies paratuberculosis status of German Holstein cows tested by fecal culture. J. Dairy Sci. 95:2734-2739. https://doi.org/10.3168/jds.2011-4994.

Lombard, J. E. 2011. Epidemiology and economics of paratuberculosis. Vet. Clin. North Am. Food Anim. Pract. 27:525-535. https://doi .org/10.1016/j.cvfa.2011.07.012.

Lombard, J. E., I. A. Gardner, S. R. Jafarzadeh, C. P. Fossler, B. Harris, R. T. Capsel, B. A. Wagner, and W. O. Johnson. 2013. Herd-level prevalence of Mycobacterium avium ssp. paratuberculo- sis infection in United States dairy herds in 2007. Prev. Vet. Med. 108:234-238. https://doi.org/10.1016/j.prevetmed.2012.08.006.

Madsen, P., and J. Jensen. 2013. A user's guide to DMU. A package for analyzing multivariate mixed models. Version 6. release 5.2 . Center for Quantitative Genetics and Genomics, Dept. of Molecular Biology and Genetics, University of Aarhus, Research Centre Foulum, Tjele, Denmark.

Mortensen, H., S. S. Nielsen, and P. Berg. 2004. Genetic variation and heritability of the antibody response to Mycobacterium avium subspecies paratuberculosis in Danish Holsteins cows. J. Dairy Sci. 87:2108-2113. https://doi.org/10.3168/jds.S0022-0302(04)70029 $-6$.

Muskens, J., H. W. Barkema, E. W. Russchen, C. van Maanen, Y. H. Schukken, and D. Bakker. 2000. Prevalence and regional distribution of paratuberculosis in dairy herds in the Netherlands. Vet. Microbiol. 77:253-261.

National Animal Health Monitoring System (NAHMS). 2007. Part I: Reference of Dairy Health and Management in the United States. USDA, Animal and Plant Health Inspection Service, Veterinary Service, Center for Epidemiology and Animal Health, Fort Collins, CO.

Nielsen, S. S. 2009a. Parameters used to assess the efforts to control paratuberculosis in Denmark. Pages $14-20$ in Monitoring success of paratuberculosis programs: Proc. 2nd Paratuberculosis Forum. Minneapolis, MN. IDF, Brussels, Belgium.

Nielsen, S. S. 2009b. Paratuberculosis in dairy cattle - Epidemiological studies used for design of a control programme in Denmark. Dr. Med. Vet. Thesis. Department of Large Animal Sciences. University of Copenhagen, Denmark.

Nielsen, S. S. 2009c. Programmes on Paratuberculosis in Europe. Pages 101-108 in Proc. 10th Int. Colloq. Paratuberculosis, Minneapolis, MN. Univ. of Minnesota, Minneapolis.

Nielsen, S. S., H. Bjerre, and N. Toft. 2008. Colostrum and milk as risk factors for infection with Mycobacterium avium subspecies paratuberculosis in dairy cattle. J. Dairy Sci. 91:4610-4615. https://doi .org/10.3168/jds.2008-1272.

Ott, S. L., S. J. Wells, and B. A. Wagner. 1999. Herd-level economic losses associated with Johne's disease on US dairy operations. Prev. Vet. Med. 40:179-192.

Shook, G. E., M. Chaffer, X. L. Wu, and E. Ezra. 2012. Genetic parameters for paratuberculosis infection and effect of infection on production traits in Israeli Holsteins. Anim. Genet. 43(Suppl. 1):56-64. https://doi.org/10.1111/j.1365-2052.2012.02349.x.

Sun, D. X., J. Jia, Y. Ma, Y. Zhang, Y. C. Wang, Y. Yu, and Y. Zhang. 2009. Effects of DGAT1 and GHR on milk yield and milk composition in the Chinese dairy population. Anim. Genet. 40:997-1000.

Sun, Y., S. C. Ma, H. Dong, and X. Y. Wang. 2015. Serological investigation and analysis of bovine paratuberculosis in some provinces of China. Progress in Veterinary Medicine 36:118-120.

Tiwari, A., J. A. VanLeeuwen, S. L. McKenna, G. P. Keefe, and H. W. Barkema. 2006. Johne's disease in Canada. Part I: Clinical symptoms, pathophysiology, diagnosis, and prevalence in dairy herds. Can. Vet. J. 47:874-882.

van Hulzen, K. J., M. Nielen, A. P. Koets, G. de Jong, J. A. van Arendonk, and H. C. Heuven. 2011. Effect of herd prevalence on heritability estimates of antibody response to Mycobacterium avium subspecies paratuberculosis. J. Dairy Sci. 94:992-997. https://doi .org $/ 10.3168 /$ jds.2010-3472.

Whitlock, R. H., and C. Buergelt. 1996. Preclinical and clinical manifestations of paratuberculosis (including pathology). Vet. Clin. North Am. Food Anim. Pract. 12:345-356.

Zare, Y., G. E. Shook, M. T. Collins, and B. W. Kirkpatrick. 2014. Short communication: Heritability estimates for susceptibility to Mycobacterium avium subspecies paratuberculosis infection defined by ELISA and fecal culture test results in Jersey cattle. J. Dairy Sci. 97:4562-4567. https://doi.org/10.3168/jds.2013-7426. 